\title{
Endogenous Inflows of Speculative Capital and the Optimal Currency Appreciation Path
}

\author{
Mei Li, Junfeng Qiu*
}

\begin{abstract}
This paper examines the optimal appreciation path of an under-valued currency in the presence of speculative capital inflows that are endogenously affected by the appreciation path. A central bank decides the optimal appreciation path based on three factors: (i) Misalignment costs associated with the gap between the actual exchange rate and the fundamental exchange rate, (ii) short-term adjustment costs due to fast appreciation, and (iii) capital losses due to speculative capital inflows. We examine two cases in which speculators do and do not face liquidity shocks. We show that, in the case without liquidity shocks, the central bank should appreciate quickly to discourage speculative capital, and should appreciate more quickly in initial periods than in later periods. In the case with liquidity shocks, the central bank should pre-commit to a slow appreciation path to discourage speculative capital. The central bank should appreciate slowest when the probability of liquidity shocks takes middle values. If the central bank cannot commit and can only take a discretionary policy, appreciation should be faster.
\end{abstract}

Journal of Economic Literature Classification: F31, F32

Keywords: exchange rate, appreciation, capital flows

${ }^{*}$ Department of Economics, College of Management and Economics, University of Guelph, Guelph, Ontario, Canada N1G 2W1, mli03@uoguelph.ca; and CEMA, Central University of Finance and Economics, Beijing, China, 100081, qiujunfeng@cufe.edu.cn. 


\section{Introduction}

An important phenomenon in the global economy since 2000 has been the global imbalance characterized by increasing international reserves in some developing countries and huge current account deficits in the US. The accumulation of international reserves in these developing countries is accompanied by the appreciation anticipation on their currencies, which leads to a large amount of speculative capital inflows. Speculative capital inflows may result in some unfavorable outcomes. For example, the appreciation premium that speculative capital earns from appreciation exactly equals the capital losses of a central bank. Moreover, speculative capital inflows can lead to rapid growth in money supply as the central bank has to purchase foreign exchanges using the domestic currency, increasing the inflation pressure domestically.

One of the typical examples is China. China experienced an exchange rate regime switch in July 2005, when it stopped an effective peg to the US dollar and started to appreciate its under-valued currency. The appreciation path is shown in Figure 1. The initial appreciation right after July 2005 was quite slow. It became faster in 2007 and the first half of 2008. The appreciation has essentially stopped since the middle of 2008, when the global economic slowdown triggered by the global financial crisis started to hit China's exports and economic growth.

During the appreciation process, a strong anticipation about the appreciation of Chinese Yuan attracted a large amount of speculative capital inflows. A rapid buildup of international reserves was observed. In particular, the total reserves almost doubled during 2007 and 2008. The increase in reserves was caused by surpluses in both the current and capital account. Many economists in China speculated that at least part of the current and capital account surpluses was actually hot money, that is, speculative capital inflows that take advantage of higher asset returns in China. ${ }^{1}$

\footnotetext{
${ }^{1}$ Zhang (2008) argued that hot money could be as high as 228.2, 207.8 and 385.1 billion US dollars in 2005, 2006 and 2007, respectively, with a total of 821.1 billion dollars. Although China still imposes strict regulations over capital flows, most hot money actually came into China legally, through ways such as over-reporting the income from exports, and reporting capital used for speculative purposes as foreign direct investment.
} 


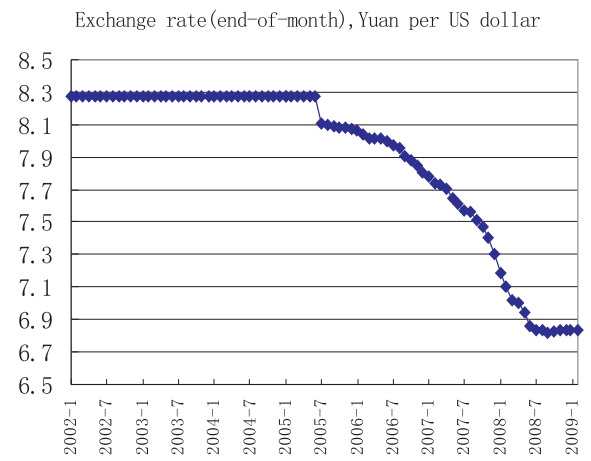

(a) Exchange Rate

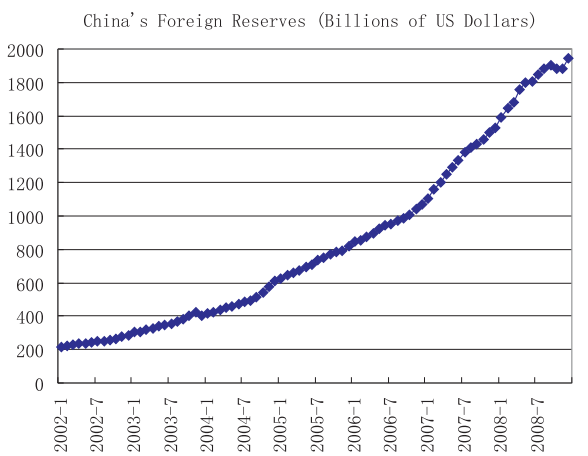

(b) Total Foreign Exchange Reserves

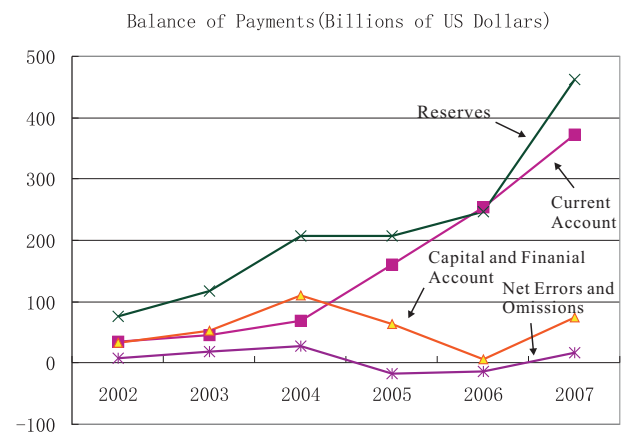

(c) Balance of Payments

Figure 1: (a) The exchange rate, (b) the foreign reserves and (c) the balance of payments of China. Data source: State Administration of Foreign Exchange. http://www.safe.gov.cn. Note: At the time of writing this paper, the annual data for the balance of payments of 2008 is not published yet. For the first half of 2008, the current account had a surplus of 191 billions US dollars; the capital and financial account had a surplus of 72 billions US dollars.

One of the key ways to solve the problems in those developing countries with the appreciation pressure is to appreciate their under-valued currencies. Their central banks need to find an optimal appreciation path to minimize their costs during the appreciation process. We find this issue especially interesting not only because it is important for those developing countries, but also because it has important effects on the US economy. This can explain why China's appreciation policy is often at the center of political debate between the US and China, considering that China is the largest trading partner of the 
US. The debate between these two countries is often characterized by the US's eagerness to see a fast appreciation in Chinese Yuan and China's resistance to it. Here we do not intend to explore the question of whether a fast appreciation in Chinese Yuan will benefit the US economy or not. Instead, the question we ask is whether, even from the perspective of the developing countries, a faster appreciation necessarily causes more damage to those countries. In other words, what should be an optimal appreciation policy for those countries? In order to answer this question, we need some theoretical guidance.

Unfortunately, research on this issue is still in its infancy. Most previous research focuses on the strategic interaction between central banks and speculators, when central banks attempt to prevent a flight of capital out-of a country whose currency is under the pressure of depreciation. Seminar papers in this strand of literature, known as the currency crisis literature, include Krugman (1979), Flood and Garber (1984), Obstfeld (1986), Morris and Shin (1998), and Chang and Velasco (2001). The major contribution of our paper is that we analyze the optimal appreciation policy for an under-valued currency when the central bank attempts to deter capital from flowing into the country. To our knowledge, our paper is the first to address this issue using a formal model. By doing so, we hope that our paper can provide theoretical guidance for the central banks with the appreciation pressure to design an optimal appreciation policy.

In our model, a central bank needs to design an optimal appreciation path towards its long-run equilibrium level for its under-valued currency. The central bank is concerned about three types of costs when deciding on its policy. The first cost is the misalignment cost proportional to the gap between the current exchange rate and the long-run equilibrium level. This cost captures the welfare losses associated with resource misallocations due to currency mispricing. The second cost is the capital losses of the central bank due to the appreciation premium earned by speculators. This cost captures the losses associated with speculative capital inflows. The third cost is the adjustment cost which is increasing in the appreciation size in each period. This cost captures the short-term frictional costs. For example, some workers in the export sector may lose their jobs due to appreciation, and it takes time for the workers to be absorbed by other sectors.

We assume speculation is costly, and capital inflows are endogenously affected by the 
anticipated future returns on speculation. Thus, speculators will take the central bank's policy into account when deciding how much to invest. In turn, the central bank will take into account the response of the speculators when deciding its policy. That is, speculative capital inflows are endogenously determined in our model.

We consider two cases, one in which speculators do and one in which they do not face liquidity shocks. In the case without liquidity shocks, speculators can stay until the appreciation is completed. In the case with liquidity shocks, speculators face a positive probability of being hit by a liquidity shock in each period, which will force them to withdraw their capital out of the country. We believe that liquidity shocks are an important factor affecting the movement of speculative capital. For example, the recent liquidity crunch in most developed countries can definitely change the pattern of speculative capital flows greatly. More importantly, the introduction of liquidity shocks captures the fact that speculators may face a short-term investment horizon in reality.

Our paper produces some important results as follows:

1.In the case without liquidity shocks, the central bank should appreciate as fast as possible to deter capital inflows. A slower appreciation can only attract more capital inflows. However, in the case with liquidity shocks, it is possible that a slower appreciation can actually discourage capital inflows.

2.In the case without liquidity shocks, the central bank should appreciate faster in initial periods than in later periods.

3.In the case with liquidity shocks, it is optimal for the central bank to pre-commit itself to an optimal appreciation path, as opposed to taking a discretionary appreciation policy without commitment. We also find that appreciation should be faster when the central bank carries out a discretionary policy period by period.

4.Appreciation should be slowest when the probability of liquidity shocks takes the middle values. Appreciation should be faster when the probability of a liquidity shock is either extremely low or extremely high.

We find that the first result is especially important in reality. There has been a 
heated debate about how to design the optimal appreciation path for Chinese Yuan in China, and the concern about speculative capital inflows is at the center. One opinion argues that China should appreciate fast because once the appreciation is completed, no more speculative capital induced by the anticipation of appreciation will flow in. An alternative opinion is that appreciation should be slow, because by doing so, the expected rate of return on capital inflows will be lower and consequently capital inflows will be discouraged. (See Lin (2007) as an example.)

Our paper confirms the first opinion in the case without liquidity shocks. In this case, capital inflows in each period are solely determined by the expectation about the total size of appreciation in the long run, rather than that in the short run. Slow appreciation will only prolong the process of appreciation, and as a result will attract more capital inflows and lead to more capital losses. However, we find that the second opinion is correct in the case with liquidity shocks. In this case, capital inflows are determined not only by total size of appreciation in the long run, but also by the exact appreciation path, because speculators may be forced to withdraw their capital in any future time due to liquidity shocks.

The rest of the paper is organized as follows. We first analyze a basic two-period model without liquidity shocks in Section 2. In Section 3, we establish a multiple-period model to generalize the results in the basic model. In Section 4, we examine the optimal policy

when speculators face liquidity shocks. Numerical examples are presented in Section 5. Section 6 concludes.

\section{The Two-Period Model without Liquidity Shocks}

We first analyze a basic two-period model to illustrate the intuition. Later, we will generalize the model to a multiple-period one. 


\subsection{The Environment}

Consider an economy with an under-valued currency. A central bank has to appreciate its currency from $E_{0}$ to $\bar{E}$ within 2 periods, with $E_{0}>\bar{E}$. Here the exchange rate is quoted as the units of the domestic currency needed to purchase one unit of the foreign currency. For example, we can refer to the home currency as Yuan and the foreign currency as dollar. The exchange rate is the units of Yuan that are needed to purchase 1 dollar.

Let $E_{0}, E_{1}$ and $\bar{E}$ denote the exchange rate level at the beginning of period 1, the end of period 1 and the end of period 2, respectively. We define

$$
e_{1}=\frac{E_{0}}{E_{1}}-1 ; e_{2}=\frac{E_{1}}{\bar{E}}-1 ; \bar{e}=\frac{E_{0}}{\bar{E}}-1,
$$

with $\bar{e}+1=\left(e_{1}+1\right)\left(e_{2}+1\right)$. Here, $e_{1}, e_{2}$ and $\bar{e}$ can be interpreted as percentage changes in the exchange rate.

There is a continuum of speculators with size 1 . We assume that speculators are identical, acting independently and taking the same actions. A representative speculator tries to make profits from the appreciation of the currency. His profit function is given by (we measure costs and profits all in dollars):

$$
\begin{aligned}
\pi & =\left[w_{1} \frac{E_{0}}{\bar{E}}-w_{1}-c\left(w_{1}\right)\right]+\left[w_{2} \frac{E_{1}}{\bar{E}}-w_{2}-c\left(w_{2}\right)\right] \\
& =\left[w_{1} \bar{e}-c\left(w_{1}\right)\right]+\left[w_{2} e_{2}-c\left(w_{2}\right)\right]
\end{aligned}
$$

where $w_{1}$ and $w_{2}$ are the amount of speculative capital inflows in period 1 and 2 respectively. $c\left(w_{t}\right)$ is the cost associated with the speculation, which is a function of $w_{t}$. We can interpret $c$ as the transaction costs for moving capital into and out of the home country, such as the cost to circumvent a possible capital control, and the cost for arranging funds if the speculator needs to borrow money. For simplicity, throughout the paper, we assume that the interest rates in both the home and foreign country are equal to zero. (We find that the introduction of interest does not affect the major results of this paper.)

$c(w)$ is assumed to be convex to capture the fact that with higher speculative capital inflow, the marginal costs for additional speculative capital will usually be higher. More specifically, we assume $c(w)=\frac{\beta}{2} w^{2}$, with $\beta>0$. 
The central bank's cost function is given by:

$$
\begin{aligned}
C & =\Phi+C L+J \\
& =\left(\phi \bar{e}+\phi e_{2}\right)+\left[w_{1} \bar{e}+w_{2} e_{2}\right]+\frac{1}{2} \alpha\left[e_{1}^{2}+e_{2}^{2}\right]
\end{aligned}
$$

$\Phi$ is used to capture the cost due to the misalignment in the exchange rate. For example, the deviation of the exchange rate from its fundamental level can lead to a misallocation of resources. We assume that this cost is proportional to the percentage difference between the current and fundamental exchange rate, and takes a simple linear form:

$$
\Phi=\phi \bar{e}+\phi e_{2}
$$

where $\phi$ is a positive constant. This cost gives the central bank an incentive to appreciate as fast as possible. ${ }^{2}$

The second term $C L$ in Equation (3) is the central bank's capital loss, which equals the appreciation premium earned by speculators. This term is used to capture the cost associated with speculative capital inflows. As we mentioned in the introduction, speculative capital inflows may have many unfavorable outcomes. Here we confine our attention to the capital loss that they bring to the central bank. The last term $J$ is used to capture short-term damage that appreciation does to the economy. For example, a sharp currency appreciation could lead to lower exports and unemployment in the export sector. It takes time for the unemployed workers to be absorbed by other sectors. Here we assume this cost is a convex function of the size of the appreciation (in terms of percentage changes in the exchange rate in every single period). This would give the central bank an incentive to smooth the appreciation over time. $\alpha$ in Equation (3) is an exogenously given positive constant.

The problem is a two-stage game in which the central bank decides $e_{1}$ and $e_{2}$ (by choosing $E_{1}$ ). Given $e_{1}$ and $e_{2}$, speculators choose $w_{1}$ and $w_{2}$.

\footnotetext{
${ }^{2}$ In this paper, we assume that over-valuation of the domestic currency will also lead to the misalignment cost. For example, in the two-period example, if $E_{1}<\bar{E}$ and $e_{2}$ is negative, we can write the second period cost as $\phi\left|e_{2}\right|$. It is easy to show that the central bank will have no incentive to set $E_{t}<\bar{E}$ in any period in a multiple-period model. Thus, throughout the paper, we assume that $E_{t} \geq \bar{E}$.
} 


\subsection{The Optimal Choices}

We first solve the speculator's profit maximization problem given $e_{1}$ and $e_{2}$

$$
\max _{w_{1}, w_{2}} \pi=\left[w_{1} \bar{e}-c\left(w_{1}\right)\right]+\left[w_{2} e_{2}-c\left(w_{2}\right)\right],
$$

where $c(w)=\frac{\beta}{2} w^{2}$.

The optimal $w_{1}$ and $w_{2}$ are given by

$$
\begin{aligned}
w_{1} & =\frac{\bar{e}}{\beta} \\
w_{2} & =\frac{e_{2}}{\beta}
\end{aligned}
$$

Notice that the second-order condition is satisfied in this problem and a maximum solution is guaranteed.

The central bank will take the speculator's best response into consideration and minimize its cost function by choosing $e_{1}$ and $e_{2}$ :

$$
\begin{aligned}
C & =\phi \bar{e}+\phi e_{2}+\left[w_{1} \bar{e}+w_{2} e_{2}\right]+\frac{1}{2} \alpha\left[e_{1}^{2}+e_{2}^{2}\right] \\
& =\phi \bar{e}+\phi e_{2}+\frac{1}{\beta}\left[\bar{e}^{2}+e_{2}^{2}\right]+\frac{1}{2} \alpha\left[e_{1}^{2}+e_{2}^{2}\right]
\end{aligned}
$$

where we use the solutions of $w_{1}$ and $w_{2}$ from Equations (6) and (7).

Before taking the first-order derivative, we make the following assumption in order to simplify the analytical results of this two-period model.

Assumption 1. $e_{1}, e_{2}$ are small so that $e_{1}+e_{2} \approx \bar{e}$.

Since $1+\bar{e}=\left(1+e_{1}\right)\left(1+e_{2}\right)=1+e_{1}+e_{2}+e_{1} e_{2}$, when $e_{1}$ and $e_{2}$ are small, $e_{1} e_{2} \approx 0$, so $e_{1}+e_{2} \approx \bar{e}$. With this approximation, we can write $e_{1}$ as $\bar{e}-e_{2}$, and the first-order condition of $C$ with respect to $e_{2}$ gives us

$$
e_{2}=\frac{\alpha \bar{e}-\phi}{\frac{2}{\beta}+2 \alpha}
$$

when $\alpha \bar{e}-\phi>0$. Otherwise, we have the corner solution $e_{2}=0$ and $e_{1}=\bar{e}$, and the appreciation is finished within one period. Note that the second-order derivative is $\frac{2}{\beta}+2 \alpha>0$. Thus, $C$ is convex in $e_{2}$.

From the above analysis, we get the following result: 
Proposition 1. $e_{1}>e_{2}$, i.e., the home currency appreciates more quickly in period 1 than in period 2.

The proof is straightforward since

$$
e_{2}=\frac{\alpha \bar{e}-\phi}{\frac{2}{\beta}+2 \alpha}<\frac{\alpha \bar{e}-\phi}{2 \alpha}<\frac{\alpha \bar{e}}{2 \alpha}=\frac{\bar{e}}{2}
$$

The intuition is as follows. Let us consider the adjustment cost only. That is, both $\Phi$ and $J$ are zero. Then the new total cost, denoted as $\hat{C}$, is

$$
\hat{C}=\frac{1}{2} \alpha\left[e_{1}^{2}+e_{2}^{2}\right]
$$

The first-order condition gives us

$$
e_{1}=e_{2}=\frac{\bar{e}}{2}
$$

So when $\hat{C}$ depends only on the adjustment cost, the central bank would like to smooth out the changes in exchange rate evenly over two periods.

However, with the misalignment cost $\Phi$ and the capital loss $C L$, the central bank has an extra incentive to appreciate more quickly. This is reflected in the extra terms $\phi$ and $\frac{2}{\beta}$ in the optimal solution for $e_{2}$, both of which give the central bank an extra incentive to lower $e_{2} . \phi$ is the marginal decrease in the cost $\phi e_{2}$ by choosing a lower $e_{2} \cdot \frac{2}{\beta}$ captures the following two effects: first, a lower $e_{2}$ leads to a lower $w_{2}$. Second, a lower $e_{2}$ also reduces the capital loss in period 2 for any given $w_{2}$.

Note that the appreciation path does not really affect $w_{1}$ because rational speculators will decide $w_{1}$ based on $\bar{e}$, the total remaining appreciation. Taking this into consideration, the central bank will appreciate more quickly in the first period so that there will be less appreciation left in period 2 and the capital inflow in period 2 will be smaller.

In fact, if there is no adjustment cost, then it is optimal to complete the appreciation within one period. At $e_{2}=0, \Phi$ yields the minimum value $\phi \bar{e}$ and the capital loss yields the minimum value $w_{1} \bar{e}=\frac{\bar{e}^{2}}{\beta}$. 


\section{The Multiple-Period Model without Liquidity Shocks}

Now we consider the case in which the central bank needs to decide both the duration of the appreciation and the optimal size of appreciation in each period. This model differs from the previous one in that the maximum periods for appreciation in this model go to infinity, rather than being exogenously given.

Let $c_{t}$ be the cost function of the central bank in period $t$. If we define $u_{t} \equiv-c_{t}$ as the utility of the central bank in period $t$, the central bank's problem is to maximize its total utility

$$
\sum_{t=1}^{T} u_{t}=\sum_{1}^{T}\left(-c_{t}\right)
$$

where $T$ is the optimal time length of appreciation chosen by the central bank.

The period cost function $c_{t}$ turns out to be (see Appendix A.1 for a detailed derivation)

$$
c_{t}=\phi \vec{e}_{t}+\left(\frac{H_{t}}{E_{t-1}}+w_{t}\right) e_{t}+\frac{1}{2} \alpha e_{t}^{2}
$$

where $E_{t}$ denotes the exchange rate at the end of period $t$. Let $\bar{E}$ be the final exchange target. $\vec{e}_{t}=\frac{E_{t-1}}{\bar{E}}-1$ denotes the appreciation that still needs to be completed at the beginning of $t . e_{t}=\frac{E_{t-1}}{E_{t}}-1$ is the change in the exchange rate in period $t . w_{t}$ is the capital inflow in period $t$ (in dollars), and $H_{t}$ is the accumulated capital in terms of domestic currency at the beginning of period $t$. 
The Bellman equation can be written as (see Appendix A.1 for a detailed derivation) ${ }^{3}$

$$
\begin{array}{ll} 
& V\left(H_{t}, \vec{e}_{t}\right)=\max _{\vec{e}_{t+1}}\left\{u_{t}+V\left(H_{t+1}, \vec{e}_{t+1}\right)\right\} \\
\text { s.t. } & \vec{e}_{t+1}=\left(\vec{e}_{t}+1\right) /\left(e_{t}+1\right)-1 \\
& H_{t+1}=H_{t}+w_{t} E_{t-1} \\
& w_{t}=\frac{\vec{e}_{t}}{\beta}
\end{array}
$$

This is a standard dynamic programming problem in which the state variables are the remaining appreciation $\vec{e}_{t}$, and the accumulated capital $H_{t}$. The control variable is $\vec{e}_{t+1}$ (or equivalently, $e_{t}$ or $E_{t}$ ). In Section 5 , numerical examples are given to examine the details of this model.

\section{Models with Liquidity Shocks}

In this section we add liquidity shocks into the model. This assumption introduces uncertainty into the decisions of speculators and makes our model more realistic.

We assume that at the end of every period, a proportion $\lambda$ of the existing speculators will be hit by a liquidity shock, and will be forced to withdraw all of their capital out of the country. We assume that $\lambda$ is a constant so that there is no aggregate uncertainty. The agents hit by the liquidity shock are randomly chosen. In addition, we assume that after $\lambda$ of the speculators leave, a new mass of $\lambda$ speculators will arrive so that the total size of speculators always remains at 1 .

We will start with a two-period model. A more general multiple-period model will be introduced later.

\footnotetext{
${ }^{3}$ We can also write the optimization problem as one in which the central bank commits an optimal future path of the exchange rates and chooses those exchange rates once for all. This is the same as the solution of dynamic programming specified here because the capital inflow in every period depends only on the current exchange rate and not on future exchange rates. In Section 4 we show that with liquidity shocks, the solution for the optimal path is no longer the same as the solution for the dynamic programming problem because the current-period capital inflow can be affected by the path of future exchange rates and there exists a commitment problem.
} 


\subsection{A Two-period Example}

The expected profit of a speculator at the beginning of period 1 is given by

$$
E \pi=\lambda\left[w_{1}\left(\frac{E_{0}}{E_{1}}-1\right)-c\left(w_{1}\right)\right]+(1-\lambda)\left[w_{1}\left(\frac{E_{0}}{\bar{E}}-1\right)-c\left(w_{1}\right)\right]
$$

With probability $\lambda$, he will leave at the end of period 1 , and with probability $1-\lambda$, he

can stay until the end of period 2. Given the central bank's choice of $E_{1}$, the speculator will choose $w_{1}$ to maximize his expected profits. The solution is:

$$
w_{1}=\frac{\lambda e_{1}+(1-\lambda) \bar{e}}{\beta}
$$

For a speculator entering the economy at the beginning of period 2, his profit maximization problem is given by:

$$
\pi=w_{2}\left(\frac{E_{1}}{\bar{E}}-1\right)-c\left(w_{2}\right),
$$

and the solution is

$$
w_{2}=\frac{e_{2}}{\beta}
$$

The central bank's costs are given by:

$$
C=\phi \bar{e}+\phi e_{2}+\left[\lambda w_{1} e_{1}+(1-\lambda) w_{1} \bar{e}+w_{2} e_{2}\right]+\frac{1}{2} \alpha\left[e_{1}^{2}+e_{2}^{2}\right]
$$

Using the equilibrium solution of $w_{1}$ and $w_{2}$ from Equations (20) and (22), the cost function becomes

$$
C=\phi \bar{e}+\phi e_{2}+\frac{\left[\lambda e_{1}+(1-\lambda) \bar{e}\right]^{2}}{\beta}+\frac{e_{2}^{2}}{\beta}+\frac{1}{2} \alpha\left[e_{1}^{2}+e_{2}^{2}\right]
$$

The central bank will choose $e_{2}$ (and $e_{1}=\bar{e}-e_{2}$ ) to minimize $C$. The first-order condition for $e_{2}$ gives

$$
e_{2}=\frac{\left(\alpha+\frac{2 \lambda}{\beta}\right) \bar{e}-\phi}{2 \alpha+\frac{2\left(1+\lambda^{2}\right)}{\beta}}
$$

Since

$$
\frac{\partial e_{2}}{\partial \lambda}=\frac{\frac{4}{\beta}}{\left[2 \alpha+\frac{2\left(1+\lambda^{2}\right)}{\beta}\right]^{2}}\left[(1-\lambda) \alpha \bar{e}+\frac{1-\lambda^{2}}{\beta} \bar{e}+\lambda \phi\right]
$$


is positive, with higher $\lambda$, the central bank will have the incentive to delay the appreciation. The intuition is that, with higher $\lambda$, more speculators in period 1 will be forced to withdraw at the end of the first period. By setting a lower $e_{1}$ (i.e., a higher $E_{1}$ ), the central bank gives a lower capital gain to speculators in period 1, thus discouraging capital inflow $w_{1}$.

This intuition will be clearer if we look at the cost breakdown of the central bank. First, the capital loss is

$$
C L=\frac{\left[\lambda e_{1}+(1-\lambda) \bar{e}\right]^{2}}{\beta}+\frac{e_{2}^{2}}{\beta}
$$

If we set $e_{2}$ by minimizing $C L$,

$$
e_{2}=\frac{\lambda \bar{e}}{1+\lambda^{2}}
$$

The first-order derivative of $e_{2}$ with respect to $\lambda$ is positive such that $e_{2}$ is strictly increasing in $\lambda$. When $\lambda=0$, we go back to the case with no liquidity shocks, in which $C L$ is minimized at $e_{2}=0$. That is, the central bank would like to finish the appreciation as soon as possible if it only aims to cut the capital loss. This is so because a lower $e_{2}$ will reduce the second period capital loss, and will not affect the first period capital loss at all. However, with liquidity shocks, the central bank now faces a tradeoff. Lower $e_{2}$ will reduce the second period capital loss. On the other hand, it will also increase $w_{1}$ and thus the first period capital loss. With higher $\lambda$, the latter effect will be larger, and the central bank's incentive to delay appreciation is also stronger. Thus by introducing a liquidity shock, we introduce an incentive for the central bank to delay the appreciation to reduce the capital loss, which is missing in a model without a liquidity shock.

In our model, the central bank also cares about the other two costs: the cost associated with the misaligned exchange rate, $\Phi$, and the adjustment cost, $J$. The first cost always gives the central bank an incentive to appreciate as fast as possible, and the second cost gives the central bank an incentive to appreciate evenly. The optimal $e_{2}$ is derived after the central bank takes all three costs into consideration. 


\subsection{The Multiple-Period Model with Pre-committed Policy}

In the multiple-period case, the central bank will have a commitment problem, because the capital inflow in period $t, w_{t}$, will have a positive probability to leave the country in every future period. Thus, $w_{t}$ will depend not only on the total remaining appreciation $\vec{e}_{t}$, but also on the exchange rate in each future period, i.e., the exact appreciation path. Since capital inflows in earlier periods can be affected by the future appreciation path, the central bank can optimally choose to commit the future appreciation policy to affect the capital inflows in previous periods.

With a commitment problem, the solution by dynamic programming is no longer optimal. We start with the case in which the central bank has the ability to pre-commit future policies and in which agents believe that the central bank will keep its promise.

The problem of the central bank is to optimally choose the length of the appreciation $T$ and $E_{t}(t=1,2, \ldots, T-1)$ to minimize its total costs: (See Appendix A.2 for a detailed derivation.)

$$
C=\Phi+C L+J
$$

where

$$
\begin{gathered}
\Phi=\sum_{t=1}^{T} \phi \vec{e}_{t}=\sum_{t=1}^{T} \phi\left(\frac{E_{t-1}}{\bar{E}}-1\right) \\
C L=\sum_{t=1}^{T} \beta w_{t}^{2} \\
J=\sum_{t=1}^{T} \frac{\alpha}{2} e_{t}^{2}=\sum_{t=1}^{T} \frac{\alpha}{2}\left(\frac{E_{t-1}}{E_{t}}-1\right)^{2}
\end{gathered}
$$

More specifically, in Equation (31), $w_{t}$ is the equilibrium value that is endogenously determined by speculators' profit maximization problem. For $t<T$,

$$
w_{t}=\frac{1}{\beta}\left[\sum_{i=0}^{T-t-1}\left((1-\lambda)^{i} \lambda\left(\frac{E_{t-1}}{E_{t+i}}-1\right)\right)+(1-\lambda)^{T-t}\left(\frac{E_{t-1}}{E_{T}}-1\right)\right],
$$


where $E_{T}=\bar{E}$. At $t=T$,

$$
w_{T}=\frac{1}{\beta}\left(\frac{E_{t-1}}{E_{T}}-1\right)
$$

In Appendix A.2, we provide more details about how to solve this cost minimization problem. Note that with $\lambda=0$, the problem reduces to the dynamic programming problem in Section 3, because now $w_{t}$ depends only on the total remaining appreciation, and there is no commitment problem any more. Minimizing the total cost $C$ by choosing $E_{t}(t=1,2,3, \ldots)$ simultaneously is equivalent to minimizing the cost using dynamic programming.

\subsection{Discretionary Policy without Commitment}

In reality, central banks may not be able to commit to future polices due to the issue of time inconsistency. Here we analyze what will happen if the central bank cannot commit itself and carries out the discretionary policy.

More specifically, we assume that the central bank decides its policy using dynamic programming. In every period $t$, the central bank takes the current state variables (the remaining appreciation $\vec{e}_{t}$ and the accumulated capital $H_{t}$ ) as given, and chooses the policy $E_{t}$ in the current period to maximize the expected total welfare from $t$ on, knowing that it will continue to carry out the discretionary policies in all future periods.

This problem is similar to the one in Section 3, except that capital inflows are now affected by the liquidity shock. The cost of the central bank in every period is still

$$
c_{t}=\phi \vec{e}_{t}+\left(\frac{H_{t}}{E_{t-1}}+w_{t}\right) e_{t}+\frac{1}{2} \alpha e_{t}^{2}
$$


Again, let $u_{t}=-c_{t}$. The Bellman equation becomes

$$
\begin{array}{ll} 
& V\left(H_{t}, \vec{e}_{t}\right)=\max _{\vec{e}_{t+1}}\left\{u_{t}+V\left(H_{t+1}, \vec{e}_{t+1}\right)\right\} \\
\text { s.t. } & \vec{e}_{t+1}=\left(\vec{e}_{t}+1\right) /\left(e_{t}+1\right)-1 \\
& H_{t+1}=\left(H_{t}+w_{t} E_{t-1}\right)(1-\lambda) \\
& w_{t}=\frac{1}{\beta}\left[\sum_{i=0}^{T-t-1}\left((1-\lambda)^{i} \lambda\left(\frac{E_{t-1}}{E_{t+i}}-1\right)\right)+(1-\lambda)^{T-t}\left(\frac{E_{t-1}}{E_{T}}-1\right)\right], t<T \\
& w_{T}=\frac{1}{\beta}\left(\frac{E_{t-1}}{E_{T}}-1\right)
\end{array}
$$

The transition equation (38) is now different because only $1-\lambda$ of the accumulated capital in period $t$ remains in the country at the beginning of $t+1$. $w_{t}$ is given by Equations (33) and (34).

\section{$5 \quad$ Numerical Results}

In this section, numerical examples are given to provide qualitative insights about mechanisms at work in our model. The detailed programming steps for these examples are described in Appendix B. Note that we do not intend to calibrate the real economy in these examples.

We first give an example in which initially the exchange rate deviates from the equilibrium level by $50 \%$. That is, $\vec{e}_{1}=0.5 . \bar{E}$ is normalized to 1 (this does not affect the result), so the initial exchange rate is $E_{0}=1.5$. The initial total capital is assumed to be $H_{1}=0$ for simplicity.

We choose parameter values in our benchmark case as follows: $\alpha=1, \phi=0.025$ and $\beta=10$. They are chosen so that the appreciation is completed neither too quickly nor too slowly. Note that the appreciation process depends only on the relative levels of $\alpha, \phi$ and $\beta$, instead of the absolute levels. 


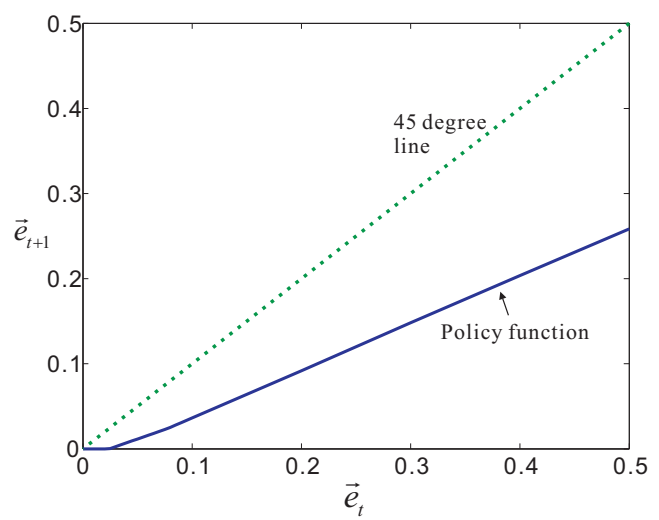

Figure 2: The policy function: Optimal $\vec{e}_{t+1}$ as a function of $\vec{e}_{t}$. $\vec{e}_{t}$ is the remaining appreciation and is given by $\frac{E_{t-1}}{\bar{E}}-1$.

\subsection{The Model without Liquidity Shocks}

Figure 2 gives the policy function: the optimal $\vec{e}_{t+1}$ as a function of $\vec{e}_{t}$. The policy function is below the 45 degree line because during the appreciation process, the remaining appreciation $\vec{e}_{t}$ is decreasing period by period. When $\vec{e}_{t}$ is very low, it is optimal to complete the appreciation process within one period so that $\vec{e}_{t+1}$ is zero.

Figure 3 shows the appreciation process for the benchmark case. One important result is that the currency should appreciate faster during initial periods and then slow down in later periods. This can be seen from changes both in $\vec{e}_{t}$ and in $e_{t}$. Recall that $w_{t}$ is increasing in $\vec{e}_{t}$. So the central bank would want to bring down $\vec{e}_{t}$ quickly so as to reduce capital inflows.

Moveover, we conducted a comparative study by varying the values of $\beta, \phi$ and $\alpha$.

Figure 4 shows the result for different values of $\beta$. Smaller $\beta$ will lead to faster appreciation in early periods and a shorter duration of the appreciation. The reason is that smaller $\beta$ means lower cost of speculation, and consequently more capital inflows. (recall that $w_{t}=\frac{\vec{e}_{t}}{\beta}$.) It also means that a decrease in $\vec{e}_{t}$ has a higher marginal effect on reducing the central bank's capital losses. Thus, with lower $\beta$ the central bank tends to appreciate faster. This result implies that in a country with an open capital market and low speculation costs, appreciation should be fast to avoid large capital inflows.

Figure 5 shows the result for different values of $\phi$. Smaller $\phi$ means smaller costs for 


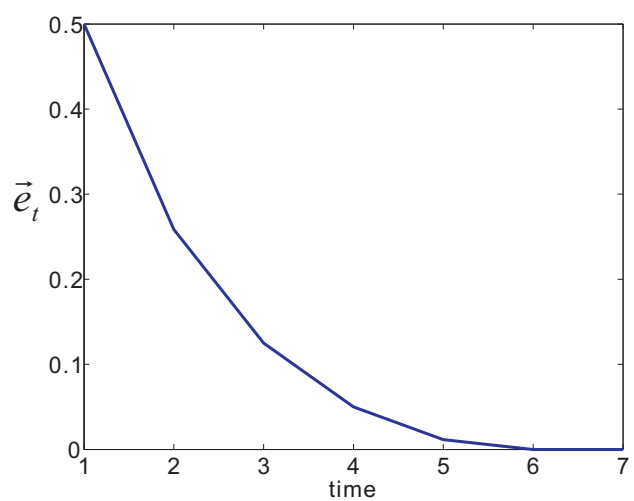

(a) $\vec{e}_{t}$

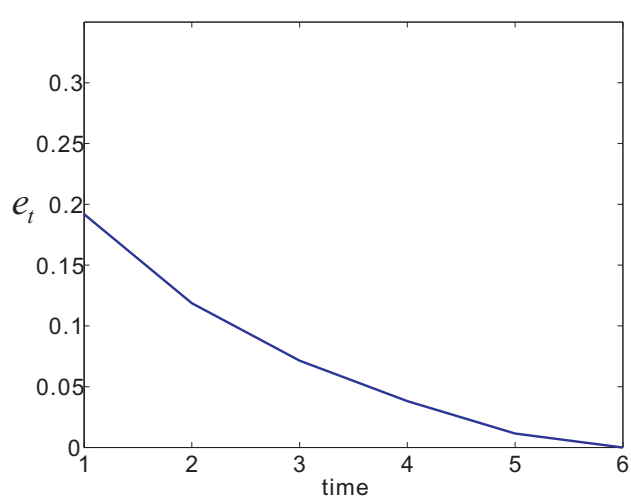

(b) $e_{t}$

Figure 3: The appreciation process for the benchmark case. $\vec{e}_{t}$ is the remaining appreciation that needs to be completed at beginning of $t$. $e_{t}$ is the percentage change in the exchange rate in $t$ measured as $\frac{E_{t-1}}{E_{t}}-1$ where $E_{t}$ is the end-of-period exchange rate.

misalignment in exchange rates, and the central bank can appreciate more slowly. This is demonstrated by Figure 5 .

The result for different values of $\alpha$ is shown in Figure 6. Higher $\alpha$ means higher adjustment costs. In this case the central bank prefers a smoother appreciation path, which is reflected in Figure 6.

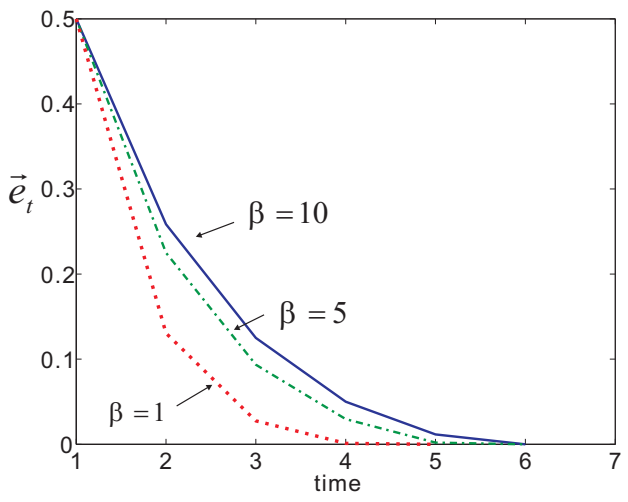

(a) $\vec{e}_{t}$

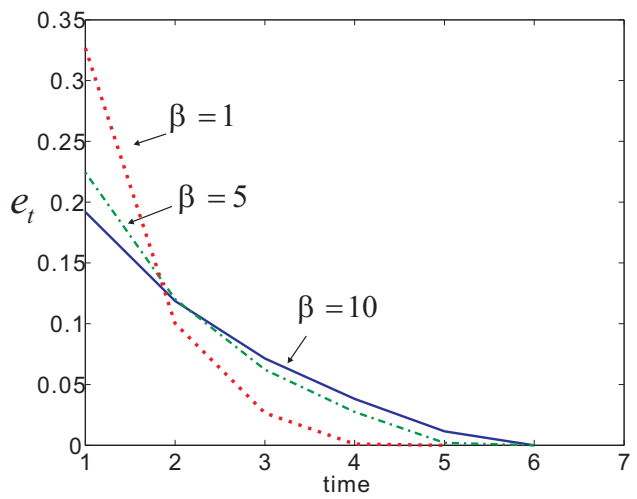

(b) $e_{t}$

Figure 4: The result for different values of $\beta$ 


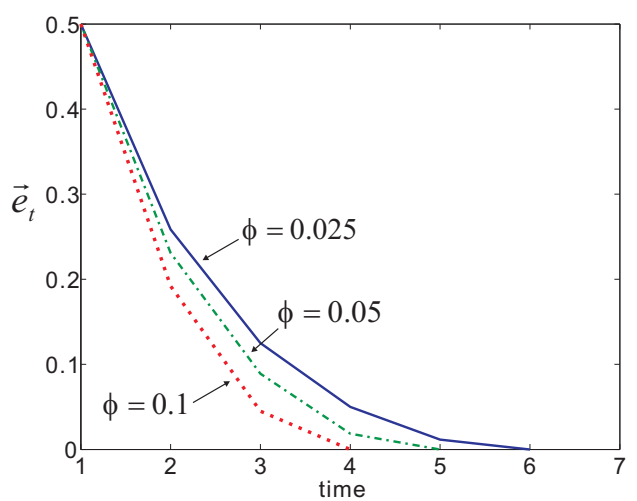

(a) $\vec{e}_{t}$

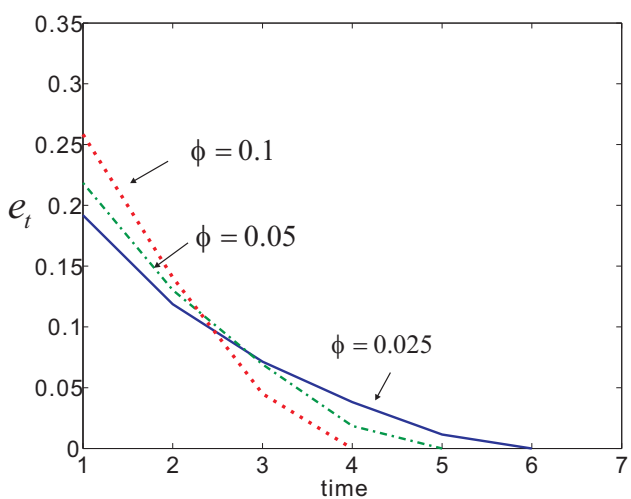

(b) $e_{t}$

Figure 5: The result for different values of $\phi$

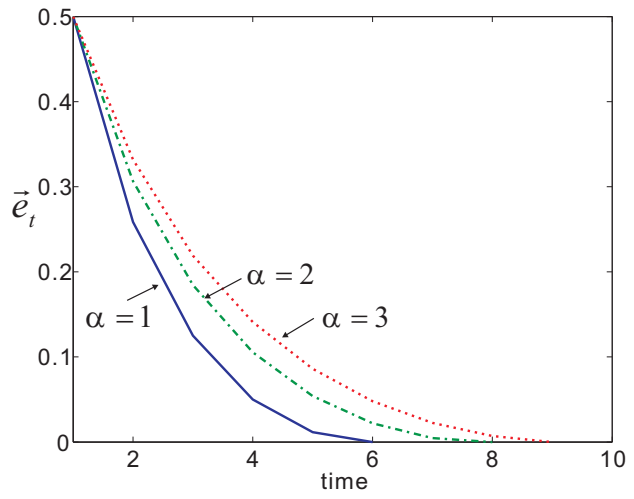

(a) $\vec{e}_{t}$

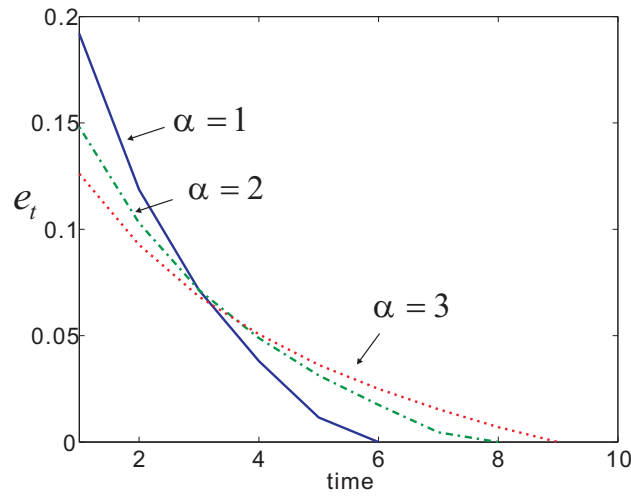

(b) $e_{t}$

Figure 6: The result for different values of $\alpha$

\subsection{Liquidity Shocks with Pre-committed Policy}

Figure 7 compares the case without liquidity shocks $(\lambda=0)$ to the case with liquidity shocks $(\lambda=0.2)$. We find when $\lambda=0.2$, the central bank appreciates more slowly and takes a longer time to complete the appreciation process. The intuition here is that due to liquidity shocks, capital inflow $w_{t}$ is now affected by the exchange rate in every future period. Thus the central bank can commit to a slower appreciation process to discourage capital inflow in earlier periods. However, in the case without liquidity shocks, capital 


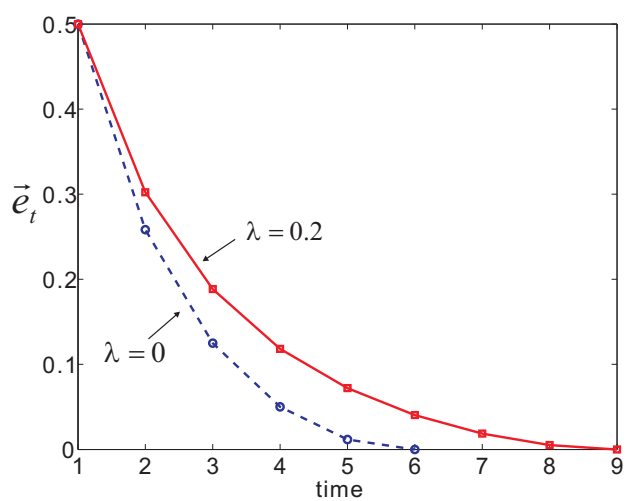

(a) $\vec{e}_{t}$

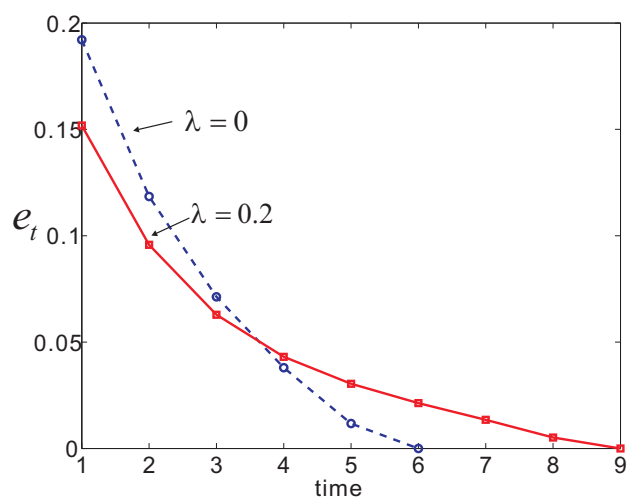

(b) $e_{t}$

Figure 7: The appreciation process when $\lambda=0$ and 0.2 .

inflow $w_{t}$ is affected only by the total size of appreciation. Therefore a slower appreciation in early periods cannot discourage capital inflows at all.

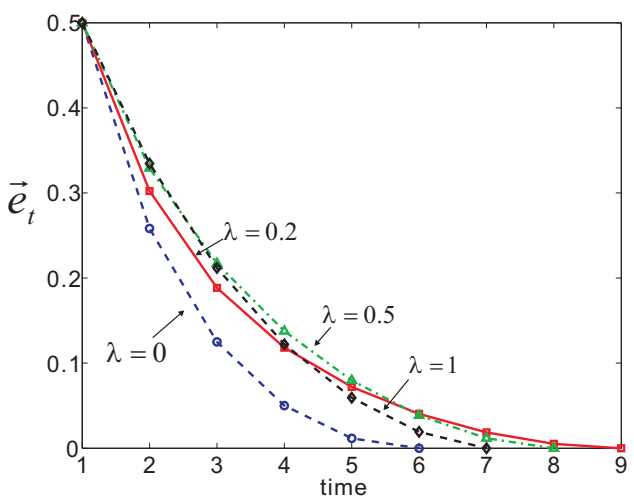

(a) $\vec{e}_{t}$

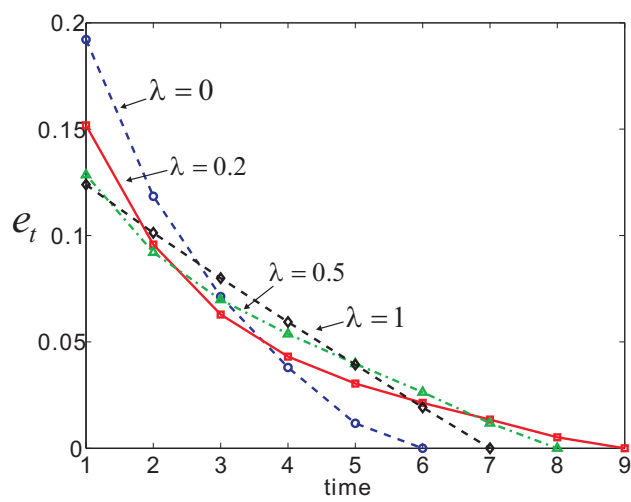

(b) $e_{t}$

Figure 8: The appreciation process for $\lambda=0,0.2,0.5$ and 1 .

Figure 8 adds two cases of $\lambda=0.5$ and 1. An interesting finding is that higher $\lambda$ does not necessarily lead to slower appreciation. In the three cases of $\lambda=1,0.5$ and 0.2 , the appreciation process takes the least amount of time when $\lambda=1$, and the most time when $\lambda=0.2$. The main reason is that with high $\lambda$, a large fraction of capital inflows in period $t, w_{t}$, will be withdrawn from the country in the very near future. Consequently, the central bank has less incentive to commit to a slow appreciation path since exchange rates in later periods have a very small effect on discouraging capital inflows in earlier 
periods.

For example, when $\lambda=1$, the capital inflow in $t, w_{t}$, will leave the country at the end of the same period. On the one hand, this means that a higher $E_{t}$ would have a strong negative effect on the capital flow $w_{t}$ at the beginning of the same period. On the other hand, $E_{t}$ would have no effect on $w_{k}(k<t)$ from all previous periods, because $w_{k}$ would have already left the country by $t$. So the central bank would have no incentive to change $E_{t}$ in order to reduce $w_{k}$.

More generally, the proportion of the capital inflow in period $t-i$ (i.e., $w_{t-i}$ ) that will leave the country in $t$ is $(1-\lambda)^{i} \lambda$. For example, when $\lambda=0.5$, the proportion of $w_{t-2}$, $w_{t-1}$, and $w_{t}$ that will leave at $t$ is $0.125,0.25$ and 0.5 , respectively. For $\lambda=0.2$, they are $0.128,0.16$ and 0.2 . So raising $E_{t}$ has a higher marginal effect on $w_{t-2}$, but a lower effect on $w_{t-1}$ and $w_{t}$ when $\lambda=0.2$ than when $\lambda=0.5$. It is easy to show that the effect on $w_{t-i}$ for $i>2$ is also higher under $\lambda=0.2$. The key point here is that if $\lambda$ is high, capital inflows in earlier periods will leave the country quickly, and raising exchange rates in later periods will have a low marginal effect on early capital inflows. This will in turn lower the central bank's incentive to slow down the appreciation.

In Figure 8, we can see that the appreciation when $\lambda=0.5$ and 1 is slower in the first period than when $\lambda=0.2$. This is because of the strong effect of the first period exchange rate $E_{1}$ on $w_{1}$ due to the high $\lambda$. However, appreciation becomes faster afterwards and takes less time to finish when $\lambda=0.5$ and 1 .

The above result implies that appreciation should be fast either when there is no liquidity shock, or when the probability of a liquidity shock is very high, and should be slow when the probability of a liquidity shock takes middle values.

\subsection{Discretionary Policy without Commitment}

Figure 9 compares the commitment case with the case of discretionary policy. It turns out that the appreciation is faster under the discretionary policy. This is because without the ability to pre-commit, the central bank will take previous capital inflows as given and only adjust the current exchange rate to minimize the future costs. The exchange rates in 


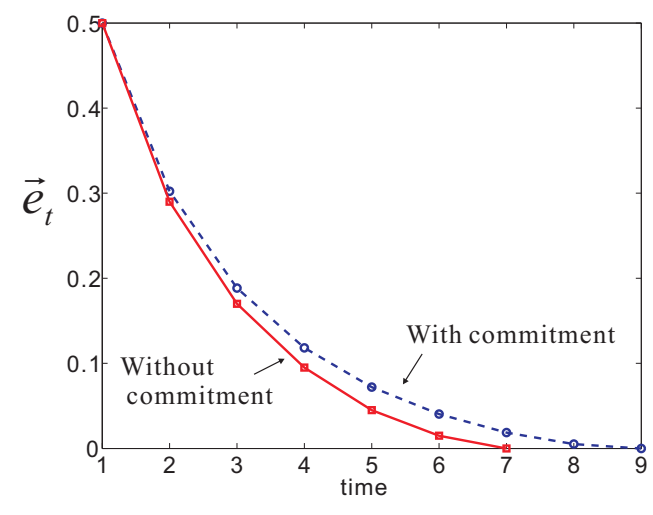

(a) $\vec{e}_{t}$

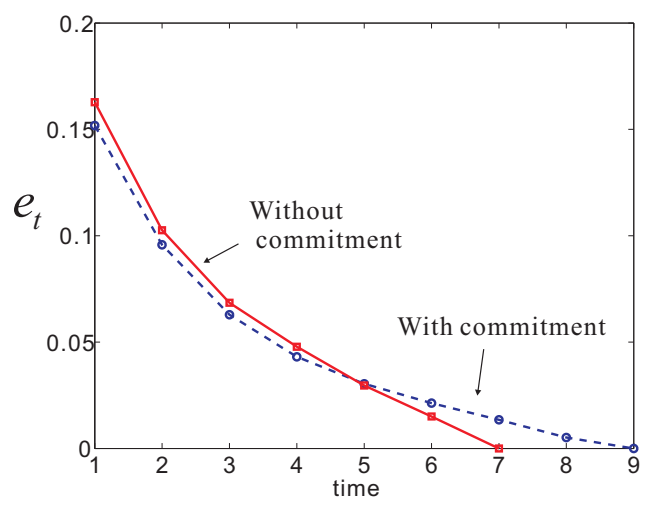

(b) $e_{t}$

Figure 9: The result when the central bank cannot pre-commit $(\lambda=0.2)$.

later periods are no longer used to discourage the capital inflows in early periods. Thus, appreciation tends to be faster than in the commitment case.

\section{Conclusions}

In this paper, we analyzed how a central bank should optimally design the appreciation path for its under-valued currency when speculative capital inflows are endogenously affected by its policy. We find when speculators face no liquidity shocks and care only about the total size of the remaining appreciation, it is optimal for the central bank to appreciate fast. Slowing down the appreciation process will only attract more capital into the country. However, when speculators face liquidity shocks, it could be optimal for the central bank to pre-commit to a slow appreciation path to discourage speculative capital.

To simplify our analysis, we assume that all information, including the central bank's cost function and the targeted exchange rate, is publicly known. In reality, asymmetric information may exist between speculators and central banks. For example, speculators may not have perfect information about the central bank's targeted exchange rate and its welfare cost function, and will have to learn it gradually from the central bank's appreciation policy. The optimal path for appreciation in this situation could be different from what we find in this paper. Moreover, the cost associated with speculative capital 
inflows in our model is captured only by capital losses of the central bank. In reality, speculative capital inflows can cause other problems such as the inflation pressure and asset bubbles in the domestic country. All these issues are worth exploring in the future. 


\section{Appendices}

\section{A Proofs}

\section{A.1 Derivations for the Dynamic Programming Problem}

This part derives the equations for the dynamic programming problem in Section 3.

The value of $w_{t}$ in terms of domestic currency is $w_{t} E_{t-1}$. So Equation (17), the transition equation for the accumulated capital $H_{t}$, is given by

$$
H_{t+1}=H_{t}+w_{t} E_{t-1}
$$

We measure all losses and profits using dollars. The capital in period $t$ (in terms of

domestic currency) is $H_{t}+w_{t} E_{t-1}$. Thus, the capital loss in period $t$ due to appreciation would be

$$
\left(\frac{H_{t}+w_{t} E_{t-1}}{E_{t}}-\frac{H_{t}+w_{t} E_{t-1}}{E_{t-1}}\right)
$$

or

$$
\begin{aligned}
& \left(\frac{H_{t}}{E_{t}}-\frac{H_{t}}{E_{t-1}}\right)+w_{t}\left(\frac{E_{t-1}}{E_{t}}-1\right)=\left(\frac{H_{t}}{E_{t-1}}+w_{t}\right)\left(\frac{E_{t-1}}{E_{t}}-1\right) \\
& =\left(\frac{H_{t}}{E_{t-1}}+w_{t}\right) e_{t}
\end{aligned}
$$

Thus we get Equation (14), the cost of the central bank in period $t$ :

$$
c_{t}=\phi \vec{e}_{t}+\left(\frac{H_{t}}{E_{t-1}}+w_{t}\right) e_{t}+\frac{1}{2} \alpha e_{t}^{2}
$$

The transition equation (16) is derived using the fact that

$$
\frac{1+\vec{e}_{t}}{1+\vec{e}_{t+1}}=\frac{\frac{E_{t-1}}{\bar{E}}}{\frac{E_{t}}{E}}=\frac{E_{t-1}}{E_{t}}=1+e_{t}
$$

Equation (18) is so because $w_{t}$ is decided according to the optimal choices of speculators. The net profit for $w_{t}$ is

$$
w_{t}\left(\frac{E_{t-1}}{\bar{E}}-1\right)-c\left(w_{t}\right)=w_{t} \vec{e}_{t}-\frac{\beta^{2}}{2} w_{t}
$$

The solution is $w_{t}=\frac{\vec{e}_{t}}{\beta}$. 


\section{A.2 Derivations for the Commitment Case}

In this part, we first prove the equations in the commitment case of Section 4.2, and then derive the optimal conditions.

Suppose the central bank optimally chooses to complete the appreciation process in $T$ periods. The exchange rate at the end of $t$ is $E_{t}$, with $E_{T}=\bar{E}$.

For $t \leq T-1$, at the beginning of period $t$, the expected profit of new speculators is

$$
\begin{aligned}
& E_{t} \pi=-c\left(w_{t}\right)+\lambda\left[w_{t}\left(\frac{E_{t-1}}{E_{t}}-1\right)\right]+(1-\lambda) \lambda\left[w_{t}\left(\frac{E_{t-1}}{E_{t+1}}-1\right)\right]+\ldots \\
& +(1-\lambda)^{T-t-1} \lambda\left[w_{t}\left(\frac{E_{t-1}}{E_{T-1}}-1\right)\right]+(1-\lambda)^{T-t}\left[w_{t}\left(\frac{E_{t-1}}{E_{T}}-1\right)\right] \\
& =-c\left(w_{t}\right)+w_{t}\left[\sum_{i=0}^{T-t-1}\left((1-\lambda)^{i} \lambda\left(\frac{E_{t-1}}{E_{t+i}}-1\right)\right)+(1-\lambda)^{T-t}\left(\frac{E_{t-1}}{E_{T}}-1\right)\right]
\end{aligned}
$$

Recall that $c\left(w_{t}\right)=\frac{1}{2} \beta w_{t}^{2}$. So the optimal choice of $w_{t}$ is

$$
w_{t}=\frac{1}{\beta}\left[\sum_{i=0}^{T-t-1}\left((1-\lambda)^{i} \lambda\left(\frac{E_{t-1}}{E_{t+i}}-1\right)\right)+(1-\lambda)^{T-t}\left(\frac{E_{t-1}}{E_{T}}-1\right)\right]
$$

Given the equilibrium $w_{t}$, the central bank's capital loss to $w_{t}$ is

$$
\begin{aligned}
& w_{t}\left[\sum_{i=0}^{T-t-1}\left((1-\lambda)^{i} \lambda\left(\frac{E_{t-1}}{E_{t+i}}-1\right)\right)+(1-\lambda)^{T-t}\left(\frac{E_{t-1}}{E_{T}}-1\right)\right] \\
= & \frac{1}{\beta}\left[\sum_{i=0}^{T-t-1}\left((1-\lambda)^{i} \lambda\left(\frac{E_{t-1}}{E_{t+i}}-1\right)\right)+(1-\lambda)^{T-t}\left(\frac{E_{t-1}}{E_{T}}-1\right)\right]^{2} \\
= & \beta w_{t}^{2}
\end{aligned}
$$

For $t=T$, the expected profit is

$$
E_{t} \pi=-c\left(w_{t}\right)+\left[w_{t}\left(\frac{E_{t-1}}{E_{T}}-1\right)\right]
$$

The optimal solution is

$$
w_{t}=\frac{1}{\beta}\left(\frac{E_{t-1}}{E_{T}}-1\right)
$$

and the associated cost to the central bank can still be written as $\beta w_{t}^{2}$. 


\section{The optimal conditions}

First, we give an analysis about the first and second order conditions, given the central bank optimally chooses to complete the appreciation in $T$ periods.

In this case, $E_{T}=\bar{E}$ at the end of $T$, and $E_{t}>\bar{E}$ for all $t<T$. The central bank must have chosen $E_{t}$ for $t<T$ so that the partial derivative of $C$ with respect to every $E_{t}(t<T)$ is equal to zero.

$$
\frac{\partial C}{\partial E_{t}}=\frac{\partial(\Phi+C L+J)}{\partial E_{t}}=0, \quad t<T
$$

Also, $E_{T}$ should be the corner solution

$$
\frac{\partial C}{\partial E_{T}} \geq 0
$$

The details of the first-order conditions are as follows.

For a particular $E_{t}$ with $t \leq T-1$, changes in $E_{t}$ only affect $\Phi$ by affecting $\vec{e}_{t+1}=\frac{E_{t}}{E}-1$, and we have

$$
\frac{\partial \Phi}{\partial E_{k}}=\frac{\phi}{\bar{E}}
$$

$E_{t}$ will affect $J$ by affecting $e_{t}$ and $e_{t+1}$. We have

$$
\frac{\partial J}{\partial E_{t}}=\alpha\left(\frac{E_{t-1}}{E_{t}}-1\right)\left(-\frac{1}{E_{t}^{2}}\right)+\alpha\left(\frac{E_{t}}{E_{t+1}}-1\right) \frac{1}{E_{t+1}}
$$

$E_{t}$ will affect $C L$ by affecting the capital inflow and the associated cost in every period up until period $t+1$. $E_{t}$ will affect $w_{k}$ for $k \leq t$ because part of $w_{k}$ will have to leave at the end of period $t$, at which point the exchange rate is $E_{t}$. $E_{t}$ also affects $w_{t+1}$ because $E_{t}$ is the beginning-of-period exchange rate for period $t+1$.

Thus, we have

$$
\frac{\partial C L}{\partial E_{t}}=\frac{\partial\left(\sum_{k=1}^{t+1} \beta w_{k}^{2}\right)}{\partial E_{t}}=\beta \sum_{k=1}^{t+1} \frac{\partial\left(w_{k}^{2}\right)}{\partial E_{t}}
$$

We need to derive $\frac{\partial w_{k}^{2}}{\partial E_{t}}$, or $2 w_{k} \frac{\partial w_{k}}{\partial E_{t}}$.

For $w_{k}$ with $k \leq t, E_{t}$ affects $w_{k}$ only through the term $E_{k+i}$, the exchange rate when $w_{k}$ has to leave at the end of period $t$, in the solution of $w_{k}$. If we set $k+i=t$, we get

$$
\frac{\partial w_{k}}{\partial E_{t}}=\frac{\partial\left(\frac{1}{\beta}(1-\lambda)^{t-k} \lambda\left(\frac{E_{k-1}}{E_{t}}-1\right)\right)}{\partial E_{t}}=-\frac{1}{\beta}(1-\lambda)^{t-k} \lambda\left(\frac{E_{k-1}}{E_{t}^{2}}\right)
$$


For $w_{k}$ with $k=t+1, E_{t}$ affects $w_{k}$ only through the term $E_{k-1}$, the beginning-ofthe-period exchange rate when $w_{k}$ enters the country, in the solution of $w_{k}$. If we set $k=t+1$, for $t \leq T-2$ (i.e., $k \leq T-1$ ), we get

$$
\begin{aligned}
\frac{\partial w_{t+1}}{\partial E_{t}} & =\frac{\partial \frac{1}{\beta}\left[\sum_{i=0}^{T-(t+1)-1}\left((1-\lambda)^{i} \lambda\left(\frac{E_{t}}{E_{t+1+i}}-1\right)\right)+(1-\lambda)^{T-(t+1)}\left(\frac{E_{t}}{E_{T}}-1\right)\right]}{\partial E_{t}} \\
& =\frac{1}{\beta}\left[\sum_{i=0}^{T-(t+1)-1}\left((1-\lambda)^{i} \lambda\left(\frac{1}{E_{t+1+i}}\right)\right)+(1-\lambda)^{T-(t+1)}\left(\frac{1}{E_{T}}\right)\right]
\end{aligned}
$$

When $t=T-1$ (i.e., $k=T$ ), we get

$$
\frac{\partial w_{t+1}}{\partial E_{t}}=\frac{\partial \frac{1}{\beta}\left(\frac{E_{t}}{E_{T}}-1\right)}{\partial E_{t}}=\frac{1}{\beta} \frac{1}{E_{T}}
$$

So for $t \leq T-2$, we have

$$
\begin{aligned}
\frac{\partial C L}{\partial E_{t}} & =\sum_{k=1}^{t}\left(-2 w_{k}(1-\lambda)^{t-k} \lambda\left(\frac{E_{k-1}}{E_{t}^{2}}\right)\right) \\
& +2 w_{t+1}\left[\sum_{i=0}^{T-(t+1)-1}\left((1-\lambda)^{i} \lambda\left(\frac{1}{E_{t+1+i}}\right)\right)+(1-\lambda)^{T-(t+1)}\left(\frac{1}{E_{T}}\right)\right]
\end{aligned}
$$

and for $t=T-1$, we have

$$
\frac{\partial C L}{\partial E_{t}}=\sum_{k=1}^{t}\left(-2 w_{k}(1-\lambda)^{t-k} \lambda\left(\frac{E_{k-1}}{E_{t}^{2}}\right)\right)+2 w_{T} \frac{1}{E_{T}}
$$

In summary, for $E_{t}$ with $t \leq T-2$, the first-order condition is

$$
\begin{aligned}
0= & \frac{\partial \Phi}{\partial E_{t}}+\frac{\partial J}{\partial E_{t}}+\frac{\partial C L}{\partial E_{t}} \\
= & \frac{\phi}{\bar{E}}+\left[\alpha\left(\frac{E_{t-1}}{E_{t}}-1\right)\left(-\frac{1}{E_{t}^{2}}\right)+\alpha\left(\frac{E_{t}}{E_{t+1}}-1\right) \frac{1}{E_{t+1}}\right] \\
& +\sum_{k=1}^{t}\left(-2 w_{k}(1-\lambda)^{t-k} \lambda\left(\frac{E_{k-1}}{E_{t}^{2}}\right)\right) \\
& +2 w_{t+1}\left[\sum_{i=0}^{T-(t+1)-1}\left((1-\lambda)^{i} \lambda\left(\frac{1}{E_{t+1+i}}\right)\right)+(1-\lambda)^{T-(t+1)}\left(\frac{1}{E_{T}}\right)\right]
\end{aligned}
$$


and for $E_{t}$ with $t=T-1$, the first-order condition is

$$
\begin{aligned}
0= & \frac{\partial \Phi}{\partial E_{t}}+\frac{\partial J}{\partial E_{t}}+\frac{\partial C L}{\partial E_{t}} \\
= & \frac{\phi}{\bar{E}}+\left[\alpha\left(\frac{E_{t-1}}{E_{t}}-1\right)\left(-\frac{1}{E_{t}^{2}}\right)+\alpha\left(\frac{E_{t}}{E_{t+1}}-1\right) \frac{1}{E_{t+1}}\right] \\
& +\sum_{k=1}^{t}\left(-2 w_{k}(1-\lambda)^{t-k} \lambda\left(\frac{E_{k-1}}{E_{t}^{2}}\right)\right)+2 w_{T} \frac{1}{E_{T}}
\end{aligned}
$$

where $w_{k}(k \in[0, T])$ is defined in Equations (45) and (48).

Now, let's analyze whether $\frac{\partial C}{\partial E_{t}}$ is increasing in $E_{t}$ or not.

$$
\frac{\partial^{2} C}{\partial E_{t}^{2}}=\frac{\partial^{2} \Phi}{\partial E_{t}^{2}}+\frac{\partial^{2} J}{\partial E_{t}^{2}}+\frac{\partial^{2} C L}{\partial E_{t}^{2}}
$$

Using (51), we have

$$
\frac{\partial^{2} \Phi}{\partial E_{t}^{2}}=0
$$

Using (52), we have

$$
\begin{aligned}
\frac{\partial^{2} J}{\partial E_{t}^{2}} & =\alpha\left[3 \frac{E_{t-1}}{E_{t}^{4}}-2 \frac{1}{E_{t}^{3}}+\frac{1}{E_{t+1}^{2}}\right] \\
& =\alpha\left[\frac{1}{E_{t}^{3}}\left(3 \frac{E_{t-1}}{E_{t}}-2\right)+\frac{1}{E_{t+1}^{2}}\right]
\end{aligned}
$$

As long as $E_{t} \leq 1.5 E_{t-1}$ (the central bank does not depreciate by 50 percent in period t), the above equation is positive. Usually, if we assume that the cost of exchange misalignment is high, the central bank will not depreciate during the appreciation process, $E_{t} \leq E_{t-1}$ and the condition is satisfied.

$\frac{\partial C}{\partial E_{t}}$ can be separated into two parts. The first part is associated with $w_{k}$ for $k \leq t$, which is

$$
\sum_{k=1}^{t}\left(-2 w_{k}(1-\lambda)^{t-k} \lambda\left(\frac{E_{k-1}}{E_{t}^{2}}\right)\right)
$$

Its derivative with respect to $E_{t}$ is

$$
\sum_{k=1}^{t}\left(-2 \frac{\partial w_{k}}{\partial E_{t}}(1-\lambda)^{t-k} \lambda\left(\frac{E_{k-1}}{E_{t}^{2}}\right)+2 w_{k}(1-\lambda)^{t-k} \lambda 2\left(\frac{E_{k-1}}{E_{t}^{3}}\right)\right)>0
$$


where we use the result of (54) that $\frac{\partial w_{k}}{\partial E_{t}}<0$ for $k \leq t$.

The second part is associated with $w_{t+1}$, which is

$$
2 w_{t+1}\left[\sum_{i=0}^{T-(t+1)-1}\left((1-\lambda)^{i} \lambda\left(\frac{1}{E_{t+1+i}}\right)\right)+(1-\lambda)^{T-(t+1)}\left(\frac{1}{E_{T}}\right)\right]
$$

for $t \leq T-2$, and $2 w_{T} \frac{1}{E_{T}}$ for $t=T-1$. Both can be written in the form of $w_{t+1} \bar{c}$, where $\bar{c}$ is a positive number that we take as given when taking the derivative. So the derivative

of the second part with respect to $E_{t}$ has the same sign as that of $\frac{\partial w_{t+1}}{\partial E_{t}}$. From (55) and (56), we know that $\frac{\partial w_{t+1}}{\partial E_{t}}>0$. As a result, $\frac{\partial^{2} C L}{\partial E_{t}^{2}}>0$.

Thus, we have

$$
\frac{\partial^{2} C}{\partial E_{t}^{2}}>0
$$

The above analysis implies that this problem has a unique solution under a reasonable assumption of the policy. More specifically, the cost function is globally convex as long as the central bank does not depreciate by more than 50 percent in any single period during the appreciation process.

So far we have demonstrated that given $T$, the optimal appreciation path is unique. Next, we show that the optimal $T$, which we denote as $T^{*}$, is also unique.

First, it can be shown that $T$ is finite. The intuition is as follows. The optimal $T$ is determined by the tradeoff between the three costs of the central bank. The main force that prevents the central bank from appreciating too fast is the adjustment cost. Because the adjustment cost is quadratic, the maximum value of the total adjustment cost is $\frac{\alpha}{2} \vec{e}_{1}^{2}$, which is the adjustment cost if the appreciation is completed in only one period. This implies that there is a limit for the reduction in the adjustment cost by prolonging the time for appreciation. In addition, if $T$ is set to be infinity, then the sum of the other two costs, the misalignment cost and the capital loss, will be infinite. This implies that the optimal $T$ is finite.

Suppose that $\bar{T}$ is known as the maximum possible value of $T$, and the optimal $T^{*}$ satisfies $T^{*} \leq \bar{T}$. The optimal case with $T=T^{*}$ can be seen a special case of $T=\bar{T}$, where the central bank takes $\bar{T}$ to complete the appreciation but it optimally sets $E_{t}=\bar{E}$ 
from period $T^{*}$ to $\bar{T}$. Using the previous analysis, we know that when $T=\bar{T}$, the optimal policy path is unique. This implies that the optimal $T^{*}$ is unique too.

\section{B Programming Steps for the Numerical Examples}

\section{B.1}

The analysis for the commitment case in the previous section implies the following steps for finding out the optimal policy path

-Start with a small $T$, and find out the optimal policy path $\left\{E_{1}, E_{2}, \ldots, E_{t-1}\right\}$ by minimizing the total cost of the central bank. Standard procedures, such as the Quasi-Newton method can be used to find out the solution (see Chapter 4 of Miranda and Fackler (2002) for an introduction).

-Increase $T$ until the central bank optimally chooses to complete the appreciation in $T^{*}$ periods, where $T^{*}<T$. That is, the central bank sets $E_{t}=\bar{E}$ from period $T^{*}$ on. The policy path associated with $T^{*}$ is then the optimal policy path.

\section{B.2}

The dynamic programming problem is solved using value function iteration with the method of discretization of the state space. A detailed introduction to this method can be found in Chapter 12 of Judd (1998).

For the case without liquidity shocks, the steps are as follows:

1.Assume that the central bank must complete the appreciation in at most $T_{\max }$ periods. Then in the last period $t=T_{\max }$, any remaining appreciation must be completed so that $e_{t}=\vec{e}_{t}$. We divide the possible ranges of the state variables into even discrete intervals. For each possible combination of the state variables $\left(H_{t}, \vec{e}_{t}\right)$, we can compute the cost function $c_{t}$ (Equation 14). We then set the value function for the last period as $V_{t}\left(H_{t}, \vec{e}_{t}\right)=-c_{t}\left(H_{t}, \vec{e}_{t}\right)$. 
2.For $t=T_{\max }-1$, for each combination of the state variables $\left(H_{t}, \vec{e}_{t}\right)$, we numerically find out the optimal choice of $\vec{e}_{t+1}$ that maximizes the value function (15).

3.Repeat the above step for $t=T_{\max }-2$, and so on.

Note that we set $T_{\max }$ high enough so that the central bank will optimally choose to finish the appreciation in $T$ periods with $T<T_{\max }$, and the constraint imposed by $T_{\max }$ is not binding.

The dynamic programming problem with liquidity shocks is slightly more complicated because $w_{t}$ cannot be directly computed from $\vec{e}_{t}$. It also depends on the future path of the exchange rate. We add the following steps:

1.Suppose we've worked out the optimal choices for all the periods after $t$. Then in period $t$, for a particular pair $\left(H_{t}, \vec{e}_{t}\right)$, try a starting value of $w_{t}$. Given $w_{t}$, and $\left(H_{t}, \vec{e}_{t}\right)$, we can find the optimal choice of $\vec{e}_{t+1}$, and the next period $\left(H_{t+1}, \vec{e}_{t+1}\right)$. This will give us the future path of the exchange rate, which is saved from previous steps. Use this future path to compute the optimal choice of capital inflow in $t$, and denote it as $\Gamma\left(w_{t}\right)$.

2.Iterate over $w_{t}$ until we find the fixed point $\Gamma\left(w_{t}\right)=w_{t}$.

The meaning of the last step is that in the equilibrium, given $w_{t}$, the central bank will choose an optimal future path of the exchange rate, and given that path, speculators will indeed choose $w_{t}$. 


\section{References}

Chang, Roberto, and Andres Velasco, 2001, "A Model of Financial Crises in Emerging Markets," Quarterly Journal of Economics, 116, 489-517.

Flood, Robert and Peter Garber, 1984, "Collapsing Exchange-rate Regimes: Some Linear Examples," Journal of International Economics, 17, 1-13.

Judd, Kenneth, 1998, Numerical Methods in Economics, The MIT Press.

Krugman, Paul, 1979, "A Model of Balance-of-payments Crises," Journal of Money, Credit and Banking, 11(3), 311-25.

Lin, Yifu, 2007, "The Fast Appreciation of Chinese Yuan May Attract More Inflows of Hot Money" (in Chinese), Beijing Morning Post, February 6th.

Miranda, Mario and Paul Fackler, 2002, Applied Computational Economics and Finance, The MIT Press.

Morris, Stephen and Hyun Song Shin, 1998, "Unique Equilibrium in a Model of SelfFulfilling Currency Attacks," American Economic Review, Vol. 88, 587-597.

Obstfeld, Maurice, 1986, "Rational and Self-fulfilling Balance-of-payments Crises," American Economic Review, 76(1), 72-81.

Zhang, Min, 2008, "The Levels and Channels of Current Hot Money Inflows in China," (in Chinese), Research Center for International Finance, Chinese Academy of Social Science, Working Paper, No. 0811. 